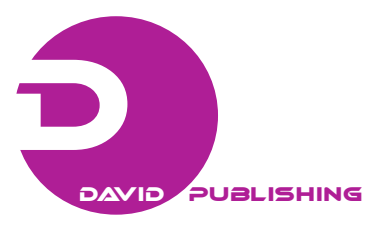

\title{
Comparative Analysis of Bridges with AASHTO and Florida I-Beam Girders
}

\author{
Peng Keke ${ }^{1,2}$ and Fikret Necati Catbas ${ }^{2}$ \\ 1. School of Environment \& Civil Engineering and Architecture, Foshan University, Foshan 528000, China \\ 2. Civil, Environmental and Construction Engineering Department, University of Central Florida, Orlando FL 32816, USA
}

\begin{abstract}
A comparative study of two pre-stressed girder bridges, one with AASHTO (American Association of State Highway and Transportation Officials) Type III girders and the other with new FIB (Florida I-beam) girders, is presented. FIB girders are expected to provide increased lateral stiffness, higher load carrying capacity, cost-efficiency and better reliability. In this paper, the first bridge that is analyzed is a 3-span bridge designed with six AASHTO Type III girders, and the second bridge has four FIB girders with the same span length, width and girder depth. The bridges are analyzed for Florida state legal loads SU4 and C5. Both bridges are analyzed using a sophisticated finite element method. The deflections, moment envelopes, section capacity and live load rating of the two bridges are obtained and compared. FIB girders have higher vertical stiffness, higher section capacity providing higher load rating than the AASHTO girders.
\end{abstract}

Key words: Florida I-beam girders, AASHTO Type III girders, deflection, capacity, load rating, finite element analysis.

\section{Introduction}

The AASHTO (American Association of State Highway and Transportation Officials) I-beam and bulb I-beam are commonly used in the State of Florida and other states as well. However, with the increases in traffic flow and other constraints (e.g., construction time, space and budget), bridge structure designs should be improved to meet the requirements of modern transportation [1, 2]. FDOT (Florida Department of Transportation), in collaboration with a university partner, developed a new pre-stressed beam called the FIB (Florida I-beam) to replace these beams in order to enhance the efficiency, to provide a larger vertical clearance and to reduce the overall cost of bridges. FIB girders are designed to have higher load carrying capacity, more efficient fabrication, safer construction, increased lateral stiffness due to their thicker top and bottom flanges. In addition, FIB girders are more economical in comparison to the

Corresponding author: Fikret Necati Catbas, Dr., Prof., research fields: structural identification, structural monitoring, bridges and structural assessment. E-mail: catbas@ucf.edu. pre-stressed beams that are currently being used. FIBs are designed to have a high concrete strength, ranging from $8 \mathrm{ksi}$ to $10 \mathrm{ksi}(55.16 \mathrm{MPa}$ to $68.95 \mathrm{MPa})$, and a large bottom flange compared to the traditional AASHTO and Bulb T-beams, allowing a larger space for more prestressing strands that are usually needed in longer span girders or wider girder spacing. Due to the capacity of the FIBs, it is also possible to reduce the number of needed beams and to reduce the bridge cost. The cost comparison of these two bridges was presented by FDOT and it is stated that FIB provides an estimated saving of about $24 \%[3,4]$. As a result, FDOT recommends FIB girders to be used in all new bridges and bridge widening designs where applicable, however AASHTO beams and Bulb T-beams will no longer be used for any new design [3]. Another advantage is that FIBs with shallower depth may be used in place of their deeper AASHTO equivalents. This in turn provides a larger vertical clearance that has been a concern for many bridges. Since, FIBs have identical top and bottom flange shapes for their full range of standard sizes, the 
only varied dimension between FIBs is the height of the web.

\section{Objectives and Scope of the Paper}

Although there is a good documentation prepared by FDOT for design charts and economic analysis, there are relatively few reports in the literature about load rating analysis of these bridges under different loading conditions comparing the capacity and response of the AASHTO and Florida I-beam girders. One recent paper outlined the development of 3D FE (finite element) models and their results for standard AASHTO Codes [5]. This type of comparative analysis is expected to be significant for selecting new bridge types and also for bridge widening designs.

In order to quantify the performance of the two different girders under special load combinations that are commonly used in Florida, FE models of two 3-span simply supported bridges with the same length, width and girder depth are developed for a comparative analysis. The deflections, moment envelopes, section capacity and live load rating of FIB bridge and the AASHTO bridge are analyzed. According to FDOT [6], critical load effects shall be created by special vehicles SU4, C5 and ST5, which are specific loads for Florida. All of the above legal loads should be applied separately. The analyses are executed for several load combinations, including Florida legal loads, SU4 or C5, separately. Based on the comparison of FEM results, some significant conclusions are obtained in this paper.

\section{Description of the Bridge Structure}

In this paper, the analyses of the bridges are based on the bridge geometries that FDOT prepared for a comparative design of two bridges. The first bridge has AASHTO Type III-beams, with 90 feet span $(27.43 \mathrm{~m})$ (6 beams with a depth of $45^{\prime \prime}(1.14 \mathrm{~m})$ and spacing of 7'-6"(2.32 m)). The other bridge has FIBs (4 beams with a depth of $45^{\prime \prime}(1.14 \mathrm{~m})$ with spacing of $11^{\prime}-9 "$ (3.63 m)), which can accomplish the same span by reducing the number of girders. Both bridges studied in this paper are simply supported prestressed concrete girder bridges with a continuous deck paving. Deck paving has a total number of three equal spans. Each span is $90-\mathrm{ft}(27.43 \mathrm{~m})$ long and supported by a 41.5 -ft $(12.65 \mathrm{~m})$ long beam cap. This beam cap is supported by three circular columns. Only two 12' $(3.65 \mathrm{~m})$ lanes are considered for traffic loading. Before modeling the bridges, all section properties and required constants are calculated and are incorporated in the models. The cross sections of two types of girders are given in Figs. 1 and 2.

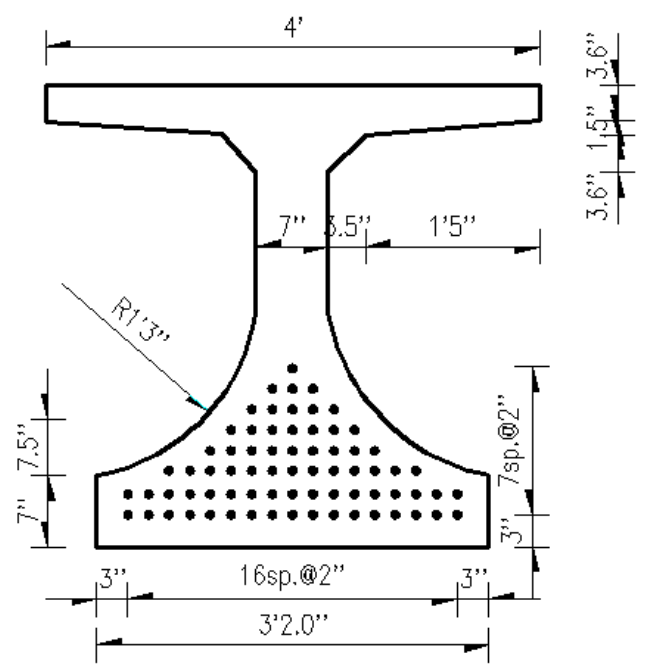

Fig. 1 Typical FIB cross-section.

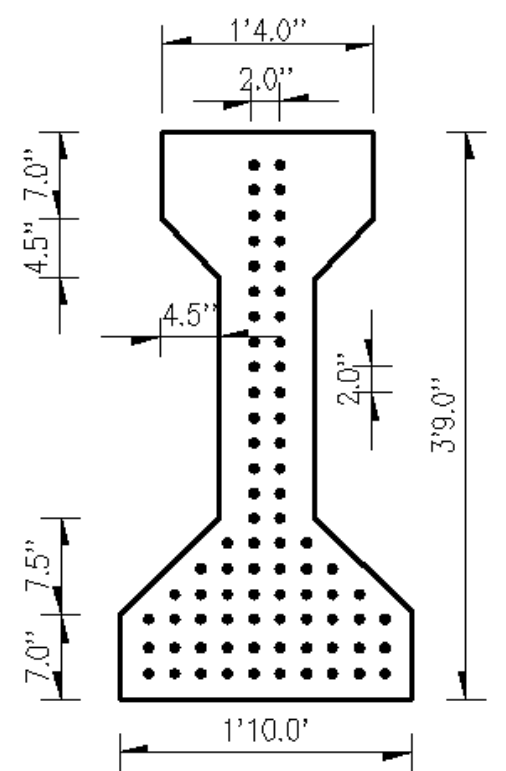

Fig. 2 Typical AASHTO Type III girder cross-section. 


\section{The Finite Element Model}

The two bridges with AASHTO Type III and FIB girders are modeled using a commercial FE package (CSI Bridge 15.2.0), which can carry out both the linear and nonlinear finite element analysis of highway bridges. It is equipped with several advanced modeling, analysis and design capabilities.

As to the two bridges studied in this paper, shell elements with three degrees of freedom are chosen to model the deck slab section. Frame elements are used to model the pre-cast pretensioned girders, the columns and the beam cap. For the AASHTO bridge, 18 pre-cast pre-tensioned AASHTO type III girders are defined with 156 strands for the entire length of the bridge. The strand distribution is given in Figs. 1 and 2. The strand arrangement remains the same in the longitudinal direction. Each girder has 26-0.6 inch (42-0.015 m) low relaxation pre-tensioned strands. For the FIB bridge, 12 pre-cast FIB girders are defined with 168 strands. Each girder has 42-0.6 inch $(42-0.015 \mathrm{~m})$ low relaxation pre-tensioned strands. Pre-tensioned strands are modeled as separate elements with 44 kips $(195.71 \mathrm{KN})$ force embedded in the precast girders to satisfy the design criteria for strength limit state. The bonded pre-tensioning strands are modeled by jacking the post-tensioned strands from both sides and specifying zero value for the curvature loss coefficient, wobble loss coefficient, and anchorage slip loss coefficient. Each bridge has three piers with $41.5 \mathrm{ft}(12.65 \mathrm{~m})$ long beam cap. The pier and the abutment foundations are assumed to be fixed for both bridges. Figs. 3 and 4 show the finite element models of AASHTO type III bridge and the FIB bridge, respectively. There are 1,009 nodes, 186 frame elements, 338 shell elements and 72 links in the FIB bridge FE model, and 1,283 nodes, 266 frame elements, 510 shell elements and 108 links in the AASHTO Type III bridge FE model. After the two FE models are finished, load cases and combinations can be defined for different design loads, state legal loads, extreme loadings or a combination of any possible loading scenario.

Deflections, live load ratings capacities and moment envelope results are described in the following sections.

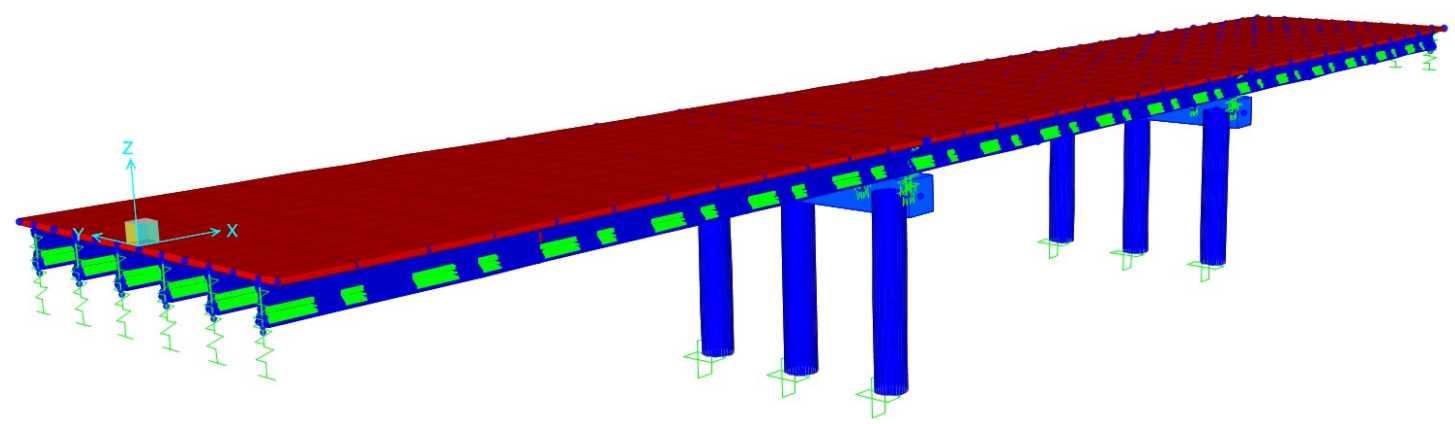

Fig. 3 The FE model of the bridge with AASHTO Type III girders.

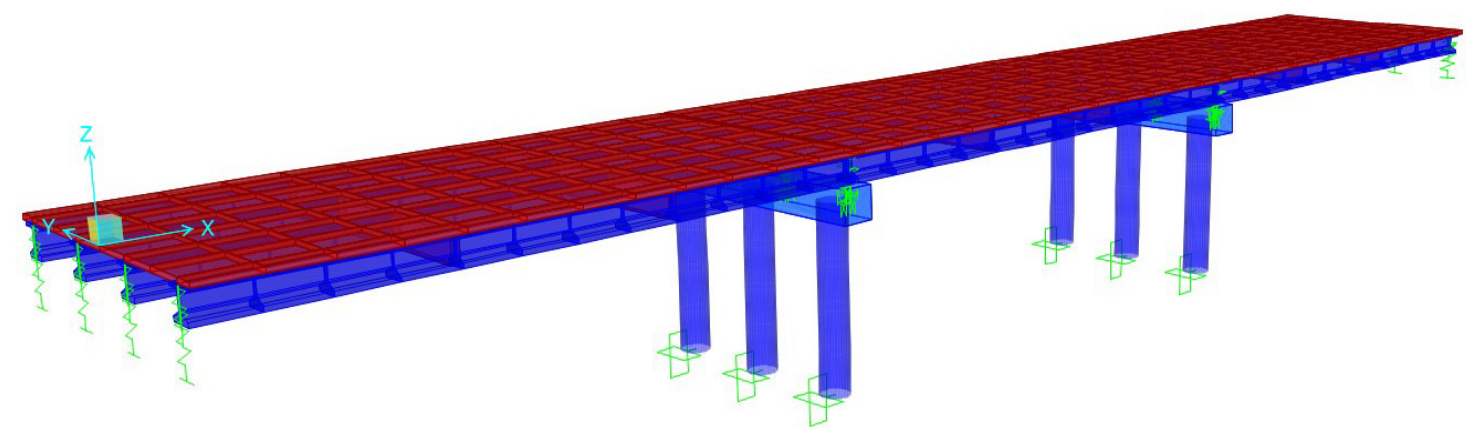

Fig. 4 The FE model of the bridge with Florida I-beam girders. 


\section{Critical State Legal Loads for Florida and Load Combinations}

According to the FDOT structures manual [6], critical load effects shall be created by SU4, C5 and ST5 Florida legal loads, when applied separately, and on each lane, not mixed with trucks. The same loading considerations and assumptions are employed for the analysis of the bridges, which are designed to carry interstate traffic in Florida. The AASHTO and FIB girder sections are evaluated for SU4 and C5 vehicular live loads (Figs. 5 and 6). These vehicle loads are multiplied by the dynamic allowance factor $(0.33)$ to consider the dynamic effect of a moving load. Six load combinations are applied on the two bridges. These six load combinations are as follows:

Combinations 1: DL + Prestress + SU4;

Combinations 2: 1.25 DL + Prestress + 1.75 SU4;

Combinations 3: 0.9 DL + Prestress + 1.75 SU4;

Combinations 4: DL + Prestress $+\mathrm{C} 5$;

Combinations 5: 1.25 DL + Prestress + 1.75 C5;

Combinations 6: 0.9 DL + Prestress + 1.75 C5.

\section{Results from the Analyses}

\subsection{The Deflections}

There are two kinds of bridge superstructure deflections to be considered. One of them is short-term deflection and the other is long-term deflection. For the long-term deflection, concrete and ambient temperatures, concrete creep and shrinkage strains, span shortening, change of strand forces, nonlinearity such as due to deterioration and boundary conditions, continuity conditions and support rotations should be considered. In many situations, site monitoring is also necessary for long term deflection [7-9]. In this section, the aim of this analysis is to compare the stiffness of the two bridges and their performance quantitatively under Florida State legal loads. Consequently, only short-term deflections are analyzed and compared. As to each of the bridges, the critical location is in the mid-span.

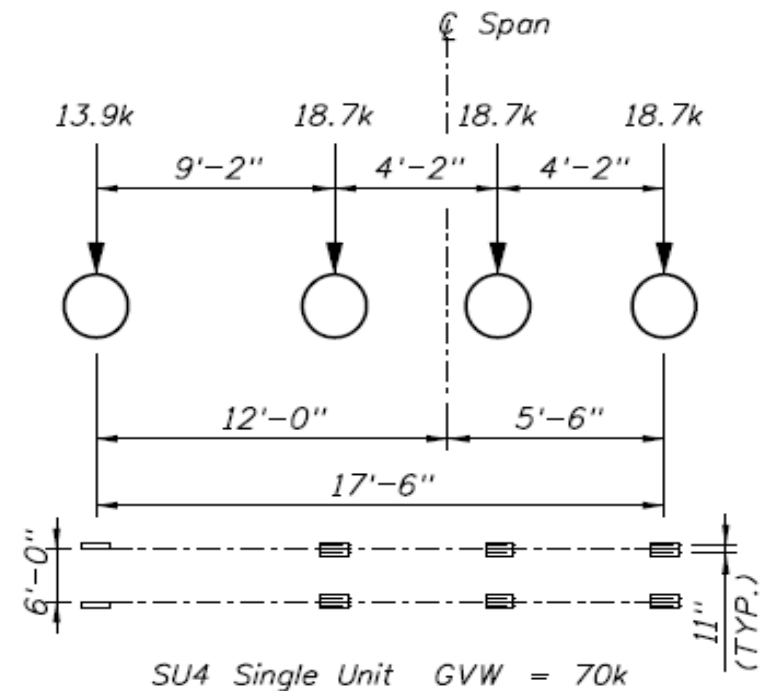

Fig. 5 The SU4 vehicle $(1 \mathrm{~K} .=4.448 \mathrm{KN}, 1 \mathrm{ft}=0.3048 \mathrm{~m})$.

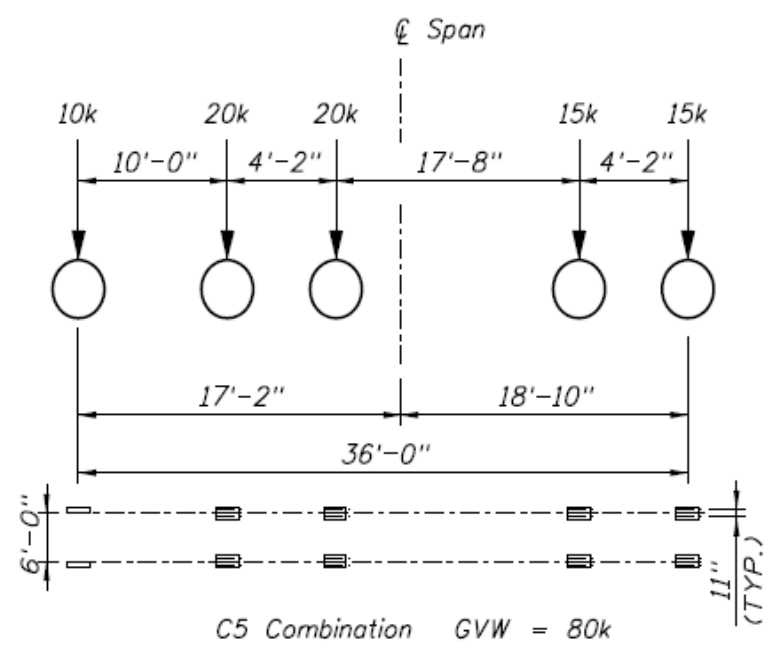

Fig. 6 The $\mathrm{C5}$ vehicle.

The deflection results at mid-span are shown in Table 1. The deflections of the AASHTO bridge and the FIB bridge under $\mathrm{C} 5$ are also shown in Figs. 7 and 8 .

According to Table 1 and Figs. 7 and 8, under the effect of load SU4, the deflection of the FIB bridge is decreased by $7 \%-9 \%$ compared with the AASHTO bridge. Under load C5, the deflection of FIB bridge is decreased by $4 \%-5 \%$ compared with the AASHTO bridge in the mid-span. The results show that FIB girders have higher vertical stiffness. Since wider flange and thicker web of FIB girder results in a higher moment of inertia, the flexural rigidity will also be higher consequently as reflected in the deflection results and comparisons. 
Table 1 The deflection of FIB bridge and AASHTO bridge under SU4 and C5 (Unit: feet $(1 \mathrm{ft}=0.3048 \mathrm{~m})$ ).

\begin{tabular}{|c|c|c|c|c|c|c|}
\hline \multirow{2}{*}{$\begin{array}{l}\text { Live load } \\
\text { Span (mid-span) }\end{array}$} & \multicolumn{3}{|c|}{ SU4 } & \multicolumn{3}{|c|}{$\mathrm{C} 5$} \\
\hline & Span 1 & Span 2 & Span 3 & $\overline{\text { Span } 1}$ & Span 2 & Span 3 \\
\hline AASHTO Type III bridge & -0.0273 & -0.0251 & -0.0272 & -0.0289 & -0.0266 & -0.0289 \\
\hline FIB bridge & -0.0249 & -0.0234 & -0.0249 & -0.0274 & -0.0256 & -0.0274 \\
\hline Comparison or difference & $9 \%$ & $7 \%$ & $8 \%$ & $5 \%$ & $4 \%$ & $5 \%$ \\
\hline
\end{tabular}

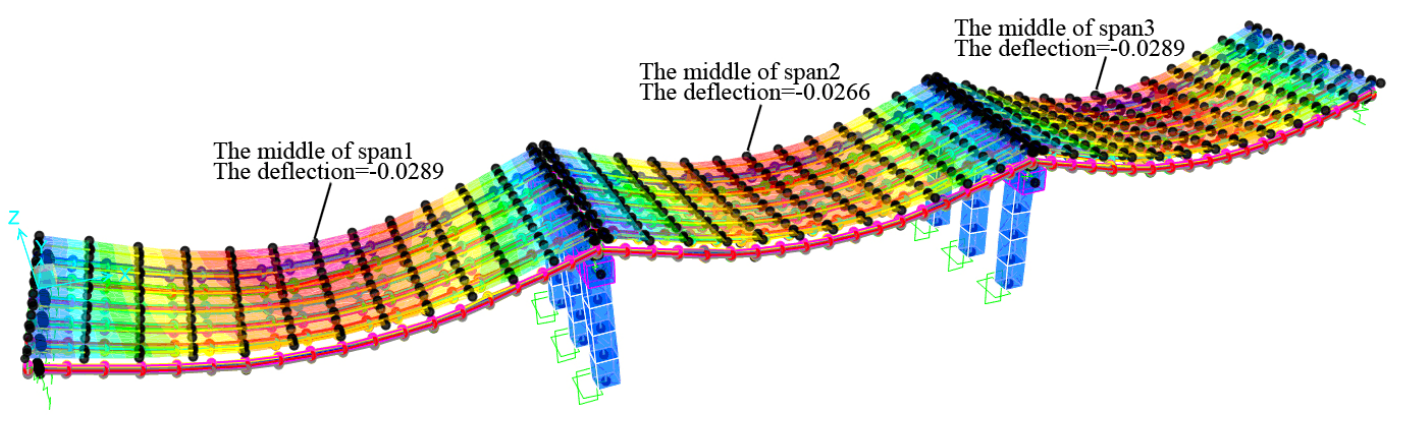

Fig. 7 The deflection of the AASHTO bridge under C5 (unit: feet).

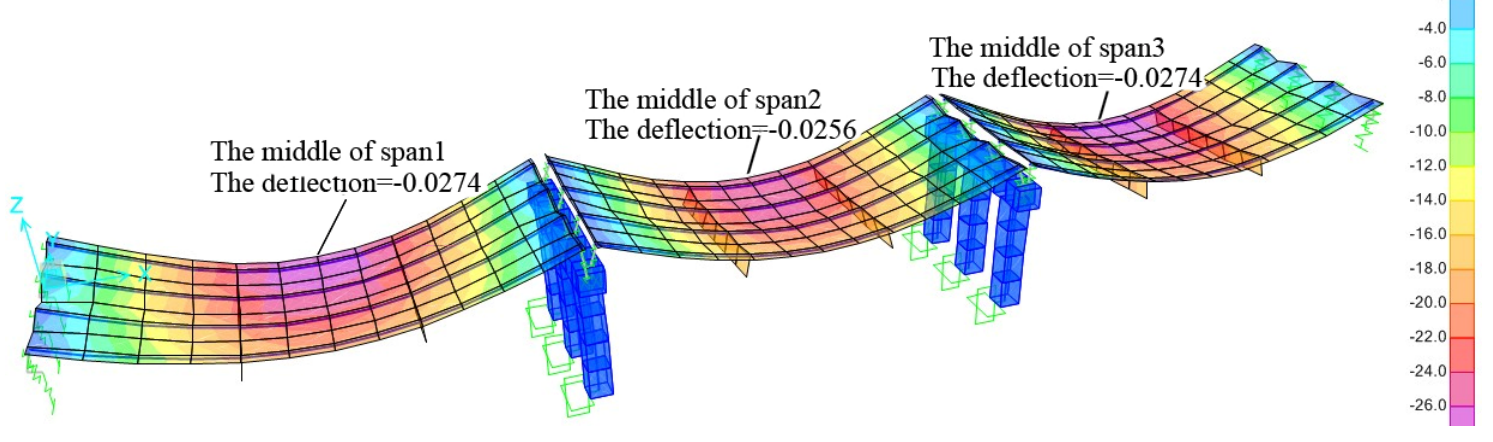

Fig. 8 The deflection of FIB bridge under C5 (unit: feet).

\subsection{Section Capacity}

In accordance with the AASHTO LRFD 2007 Code for concrete girders, section capacity and moment envelopes are analyzed. The capacity is evaluated only for bending about horizontal axis. Only positive moments are analyzed. The moment capacity is based on bonded strands and longitudinal mild steel reinforcement defined in FE models. It is assumed that all defined strands in a section, stressed or not, have $f_{\text {pe }}$ (effective stress after losses) larger than $0.5 f_{p \text { e }}$ (specified tensile strength). The capacity of the cross-section as per AASHTO formulations and the moment demand results are presented in Table 2. It should be emphasized that the section capacity results are also based on CSI Bridge software.

The moment envelope plots of AASHTO bridge and FIB bridge under second load combination (critical load case) are shown in Figs. 9 and 10, separately. According to the FE model section capacity results in Table 2, it is seen that the moment demand due to loading at FIB bridge is relatively higher than that in the AASHTO bridge by $37 \%$ for exterior girders and $53 \%$ for interior girders in average. However, the 
result shows that there is $71 \%$ higher section capacity for exterior and interior girders on the average for FIB girders. Obviously, FIB has much higher load carrying capability than AASHTO Type III girder in this case. According to Fig. 9, Fig. 10 and Table 2, the maximum moment demand of the AASHTO bridge for combinations 2, 3, 5 and 6 exceeds the section capacity, and can not meet the capability requirement. On the contrary, the capacity of FIB bridge still meets the requirement very well. It can be concluded that the additional capacity is obtained with less number of bridge girders by employing FIB for new bridges and bridge widening designs where applicable, thus AASHTO beams and Bulb T-beams will no longer be used for any new design in Florida.

\subsection{Load Rating}

Load rating is the most common approach to assess the load carrying capability of a bridge [10]. Load rating represents the current practice in bridge

Table 2 Moment values and capacity from the FEM analyses.

\begin{tabular}{|c|c|c|c|c|c|}
\hline & \multirow{2}{*}{$\begin{array}{l}\text { Moment values } \\
\text { (Unit: K.ft, } 1 \mathrm{~K} . \mathrm{ft}=1.356 \mathrm{KNm})\end{array}$} & \multicolumn{2}{|c|}{ AASHTO Type III girder } & \multicolumn{2}{|c|}{ FIB girder } \\
\hline & & Ext. girder & Int. girder & Left ext. girder & Int. girder \\
\hline Section Capacity & Capacity & $4,804.09$ & $4,863.75$ & $8,232.79$ & $8,323.49$ \\
\hline Load Combo. 1 & $\mathrm{DL}+$ Pressess $+\mathrm{SU} 4$ & $3,501.78$ & $3,110.63$ & $4,866.73$ & $4,781.26$ \\
\hline Load Combo. 2 & $1.25 \mathrm{DL}+$ Pressess $+1.75 \mathrm{SU} 4$ & $5,504.81$ & $4,820.30$ & $7,533.86$ & $7,389.30$ \\
\hline Load Combo. 3 & $0.9 \mathrm{DL}+$ Pressess $+1.75 \mathrm{SU} 4$ & $4,960.95$ & $4,276.45$ & $6,700.30$ & $6,550.73$ \\
\hline Load Combo. 4 & $\mathrm{DL}+$ Pressess $+\mathrm{C} 5$ & $3,472.57$ & $3,086.73$ & $4,830.21$ & $4,745.87$ \\
\hline Load Combo. 5 & 1.25 DL + Pressess $+1.75 \mathrm{C} 5$ & $5,453.69$ & $4,778.47$ & $7,474.96$ & $7,327.37$ \\
\hline Load Combo. 6 & $0.9 \mathrm{D} \mathrm{L}+$ Pressess $+1.75 \mathrm{C} 5$ & $4,909.83$ & $4,234.61$ & $6,636.40$ & $6,488.81$ \\
\hline
\end{tabular}

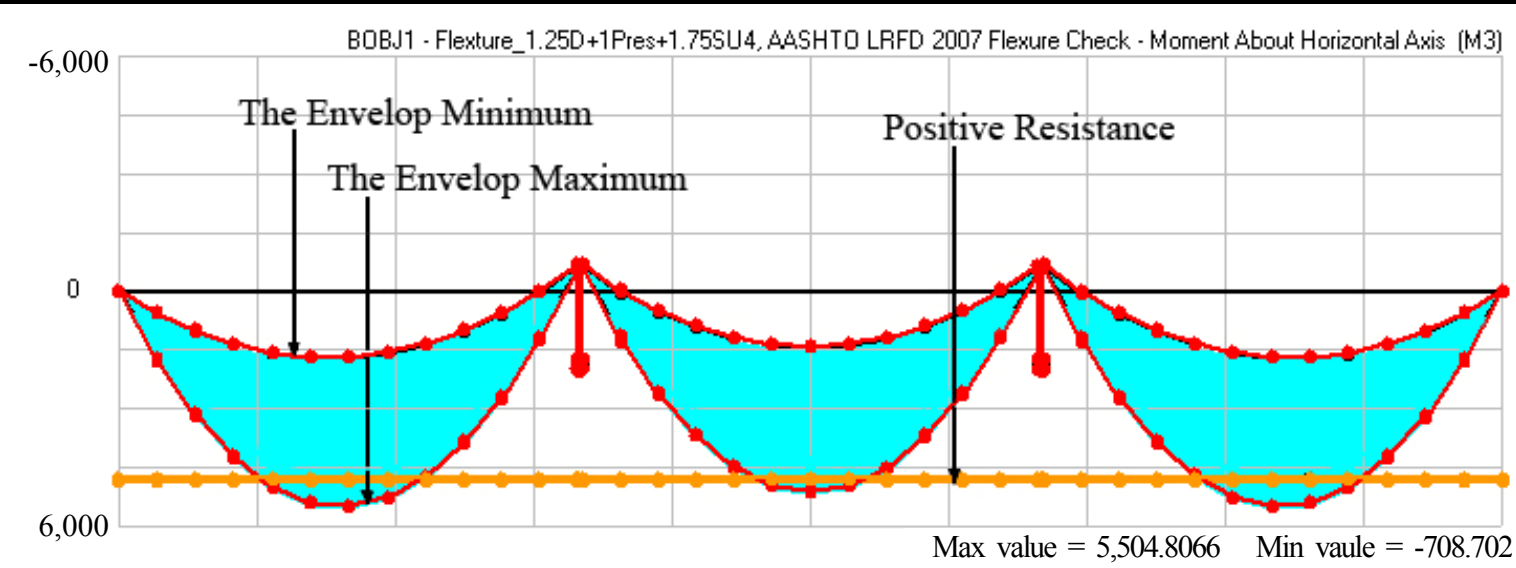

Fig. 9 Moment envelops plot of AASHTO bridge with combination 2 (Unit: K.ft).

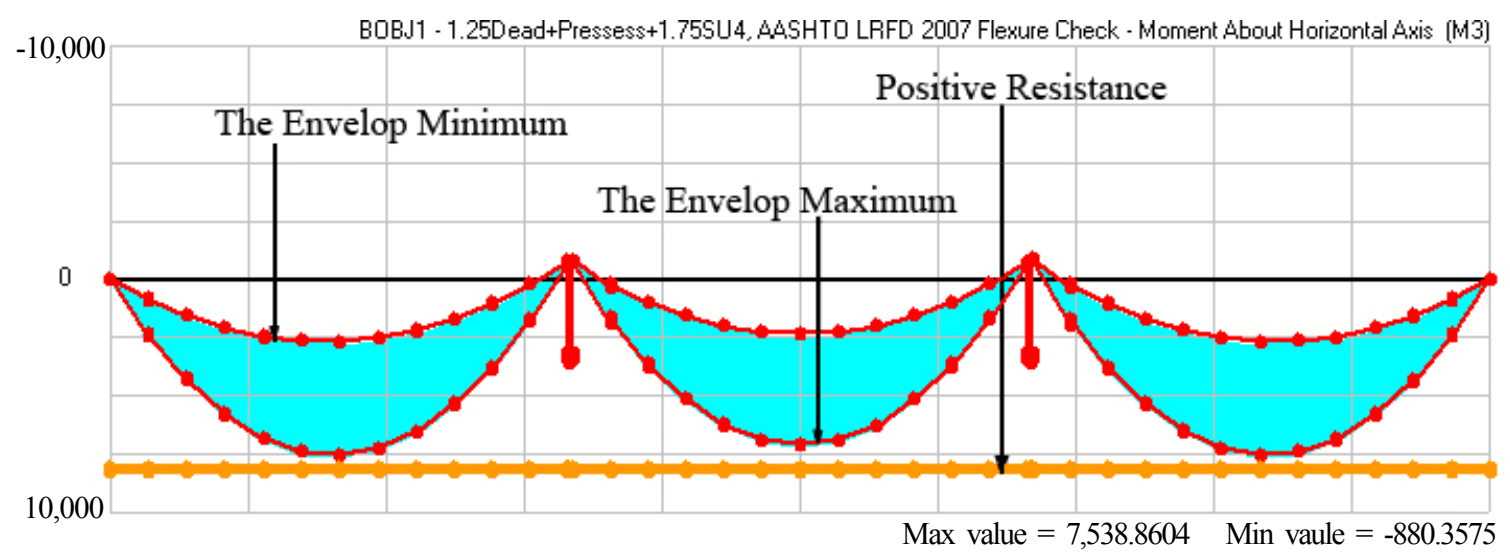

Fig. 10 Moment envelops plot of FIB bridge with Combination 2 (Unit: K.ft). 
evaluation, reliability methods, taking into account live load increase and material deterioration model, are more commonly used for lifetime bridge assessment [11].

According to FDOT structures manual [6], legal load rating should be calculated by using Florida legal loads SU4, C5 and ST5. As indicated before, only SU4 and C5 are applied, separately. Live load rating is calculated following the AASHTO Guide [12].

The load rating can be expressed as the factor of the critical live load effect to the available capacity for a certain limit state. The general formula is as follows:

$$
\begin{gathered}
R F=\frac{\text { Capacity }- \text { Deadload }}{\text { Liveload }(\text { withImpact })} \\
=\frac{(\varphi) M_{n}-\left(r_{D C}\right)\left(M_{D C}\right)-\left(r_{D W}\right)\left(M_{D W}\right)-r_{p} M_{p}}{\left(r_{L}\right)\left(M_{L L+I M}\right)}
\end{gathered}
$$

where, $R F$ is rating factor, $M_{n}$ is nominal moment resistance, $\varphi$ is resistance for flexure (default value $=$ 1.0 , in this paper, value $=1.0), r_{D C}$ and $M_{D C}$ are factored moment demand due to dead load of structural components and attachments. The $r_{D C}$ factor shall be included in the combo specified in the DC Combo demand set. In this paper, $r_{D C}=1.25, r_{D W}$ and $M_{D W}$ are factored moment demand due to dead load of wearing surface and utilities. The $r_{D W}$ factor shall be included in the combo specified in the DW Combo demand set. In this paper, $r_{D W}=1.25, r_{p}$ and $M_{p}$ are factored moment demand due to permanent loads other than dead loads. The $r_{p}$ factor shall be included in the combo specified in the P Combo demand set. In this paper, $r_{p}=1.25, r_{L}$ and $M_{L L+I M}$ are the factored moment due to live load with impact effect. The $r_{L}$ factor, which is $r_{L}=1.35$ in this paper, shall be included in the combo specified in the LL + IM Combo demand set.

This algorithm analyzes the superstructure on a girder-by-girder (beam-by-beam) basis while ignoring the effects of torsion. The C5 load ratings of the AASHTO bridge and FIB bridge are shown in Figs. 11 and 12 . The summary of the calculated load ratings for the critical locations is presented in Table 3.

According to Figs. 11 and 12, the load rating values change along the bridge length. Since the LL + IM demand set is distributed into individual girders in accordance with the live load distribution method specified in the rating formulation, each girder has different load rating. The critical location is in the mid-span, because of the fact that each span is considered as a simply supported beam with continuous deck. According to the FE model results in Table 1, the live load capacity for exterior girder is increased by $35 \%$, whereas live load capacity for interior girders increased by $23 \%$ on the average. It is shown that FIB has much higher load rating than the AASHTO Type III Girder for this case.

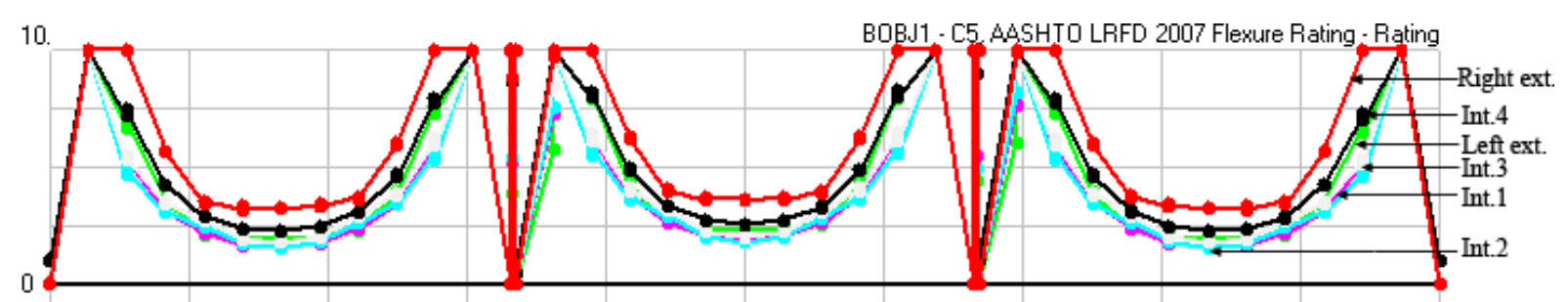

Fig. 11 The C5 load rating of the AASHTO bridge.

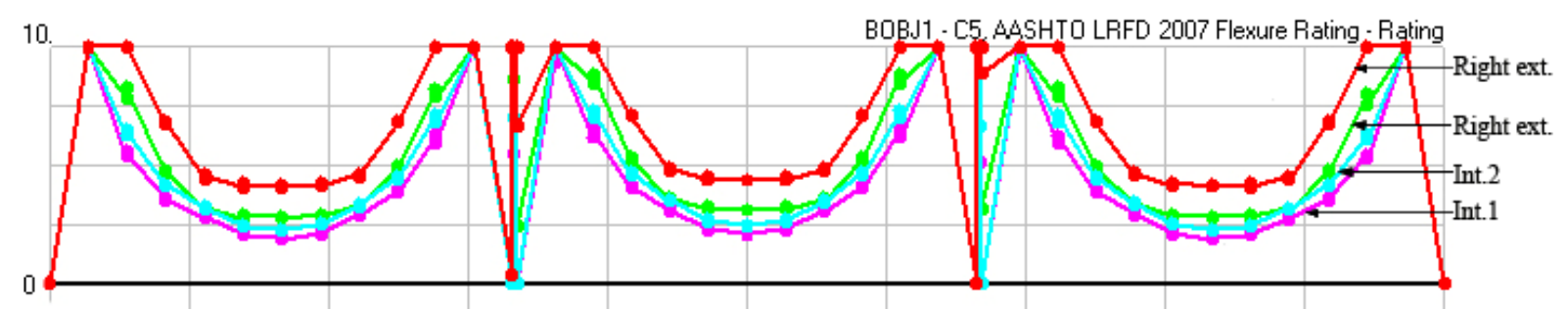

Fig. 12 The C5 load rating of the FIB bridge. 
Table 3 Load rating of the bridges.

\begin{tabular}{|c|c|c|c|c|c|c|c|c|c|c|c|}
\hline \multirow{2}{*}{ Span } & \multirow{2}{*}{$\begin{array}{l}\text { Load } \\
\text { case }\end{array}$} & \multicolumn{6}{|c|}{ AASHTO Type III girder } & \multicolumn{4}{|c|}{ FIB girder } \\
\hline & & Left-ext & Int.1 & Int. 2 & Int.3 & Int.4 & Right-ext. & Left-ext. & Int.1 & Int. 2 & Right-ext. \\
\hline \multirow{2}{*}{ Span1 } & SU4 & 2.01 & 1.50 & 1.42 & 1.63 & 2.24 & 3.45 & 2.97 & 1.81 & 2.18 & 4.48 \\
\hline & C5 & 1.93 & 1.55 & 1.54 & 1.76 & 2.26 & 3.23 & 2.79 & 1.90 & 2.27 & 4.09 \\
\hline \multirow{2}{*}{ Span2 } & SU4 & 2.38 & 1.76 & 1.64 & 1.86 & 2.52 & 3.84 & 3.27 & 1.97 & 2.35 & 4.73 \\
\hline & $\mathrm{C} 5$ & 2.30 & 1.84 & 1.79 & 2.01 & 2.56 & 3.60 & 3.11 & 2.08 & 2.45 & 4.37 \\
\hline \multirow{2}{*}{ Span3 } & SU4 & 2.01 & 1.50 & 1.42 & 1.6 & 2.24 & 3.46 & 2.97 & 1.80 & 2.17 & 4.50 \\
\hline & C5 & 1.93 & 1.55 & 1.54 & 1.76 & 2.26 & 3.24 & 2.80 & 1.89 & 2.26 & 4.11 \\
\hline
\end{tabular}

\section{Conclusions}

This study develops 3D FE models of two similar bridge types to compare deflections, section capacity, moment values, and load rating results under Florida state legal loads. One bridge has six AASHTO Type III girders and the other one has four with Florida I-beam girders, with the same length and width geometry. The following conclusions can be drawn based on the results of this research:

(1) Under load SU4, the deflection of the FIB bridge is $5 \%$ less than that of the AASHTO bridge. Under load C5, the deflection of the FIB bridge is 9\% less than that of the AASHTO bridge in average. The results show FIB girder has higher vertical stiffness;

(2) As to section capacity, the moment demand of the FIB bridge is relatively higher than that of the AASHTO bridge by $37 \%$ for exterior girders and 53\% for interior girders on the average. However, the results also show that there is $71 \%$ higher section capacity for exterior girders and interior girders on the average for FIB girders. This means that while receiving higher load demand per girder, FIB girders have higher section capacity to meet this demand;

(3) On the average, the load rating of the FIB bridge is $35 \%$ higher for exterior girders, and $23 \%$ for interior girders than that of the AASHTO Bridge. The result shows the FIB girder has higher live load carrying capability.

In conclusion, the Florida I-beam girders provide particular advantages such as increased stiffness, higher load carrying capacity, higher live load rating, and reduction in the overall cost of bridges when compared to comparable AASHTO girder bridges.

\section{Acknowledgments}

The authors would like to thank Mr. Sam Fallaha, P.E. from FDOT Structures Research Center, and Mr. Andrew DeVault, P.E. and Mr. Neil Kenis, P.E. from FDOT D5 Office for their feedback and input for the study presented in this paper. The authors would also like to acknowledge the contributions of Ms. Cara Brown for the FE model development at the initial stages of this study. Also, graduate students $\mathrm{H}$. Darwash, M. Fadul, O. Celik and M. Aghagholizadeh are appreciated for their help to the project. The first author also received the financial support from Guangdong Transportation Department. The Project numbers are 2009-03-004 and 2011-02-050.

The opinions, findings and conclusions expressed in this publication are those of the authors and do not necessarily reflect the views of the sponsoring or any other organizations.

\section{References}

[1] J. Weissman, R. Harrison, Increasing US truck size and weight regulations under NAFTA: The bridge dimension, Journal of the Transportation Research Forum 37(1) (1998) 1-14

[2] S.R. Godwin, J.R. Morris, H. Cohen, R.E. Skinner, Increasing trucking productivity within the constraints of highway and bridge design, Transportation Quarterly 41 (2) (1987) 133-155.

[3] Temporary Design Bulletin C09-01, FDOT (Florida department of Transportation), Jan. 2009.

[4] Temporary Design Bulletin C09-03, FDOT (Florida department of Transportation), June 2009.

[5] F.N. Catbas, H. Darwash, M. Fadul, M. Fadul, Modeling \& load rating of two bridges designed with 3 AASHTO and Florida I-beam girders 4, in: Transportation Research 
Board 92nd Annual Meeting, Washington, D.C., 2013, pp. 13-2212.

[6] FDOT Modifications to Manual for Condition Evaluation and LRFR (Load and Resistance Factor Rating) for Highway Bridges, FDOT Structures Manual, FDOT Florida Department of Transportation, Jan. 2010.

[7] K.C. Fu, F. Lu, Nonlinear finite-element analysis for highway bridge superstructures, Journal of Bridge Engineering 8 (3) (2003) 173-179.

[8] I.N. Robertson, Prediction of vertical deflections for a long-span prestressed concrete bridge structure, Engineering Structures 27 (12) (2005) 1820-1827.

[9] H.H. Nassif, M. Gindy, J. Davis, Comparison of laser
Doppler vibrometer with contact sensors for monitoring bridge deflection and vibration, NDT \& E International 38 (3) (2005) 213-218.

[10] A.C. Estes, D.M. Frangopol, Load rating versus reliability analysis, Journal of Structural Engineering 131 (5) (2005) 843-847.

[11] F. Akgül, D.M. Frangopol, Time-dependent interaction between load rating and reliability of deteriorating bridges, Engineering Structures 26 (12) (2004) 1751-1765.

[12] Guide Manual for Condition Evaluation and LRFR (Load and Resistance Factor Rating) of Highway Bridges, AASHTO (American Association of State Highway and Transportation Officials), 2007. 